\title{
Publisher Correction: ZNF143 provides sequence specificity to secure chromatin interactions at gene promoters
}

Swneke D. Bailey, Xiaoyang Zhang, Kinjal Desai, Malika Aid, Olivia Corradin, Richard Cowper-Sal lari, Batool Akhtar-Zaidi, Peter C. Scacheri, Benjamin Haibe-Kains \& Mathieu Lupien

Nature Communications 6:6186 doi: 10.1038/ncomms7186 (2015); Published 3 Feb 2015; Updated 10 Apr 2018

The original HTML version of this Article had an incorrect volume number of 2; it should have been 6 . This has now been corrected in the HTML; the PDF version of the Article was correct from the time of publication. 